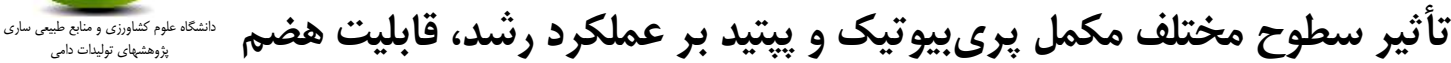

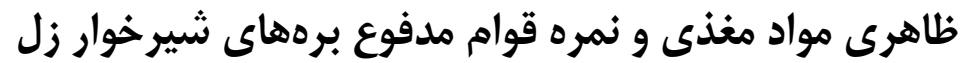

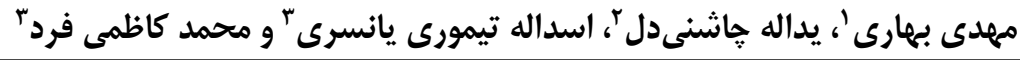

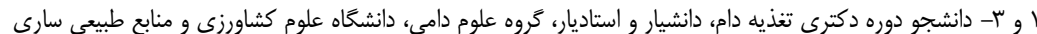

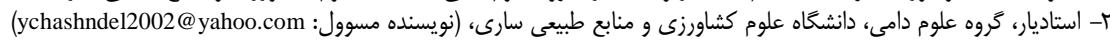

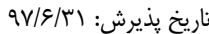 \\ تاريخ دريافت: TV/T/TV \\ صفحه: سه تا F
}

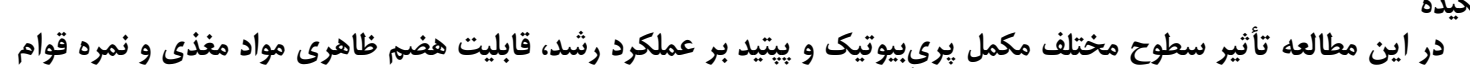

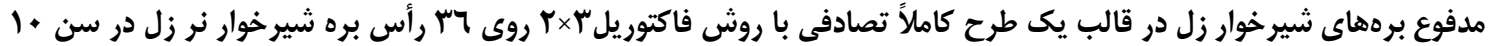

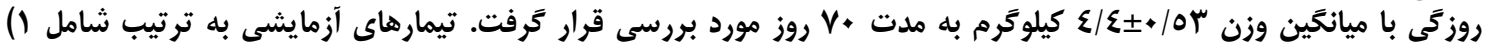

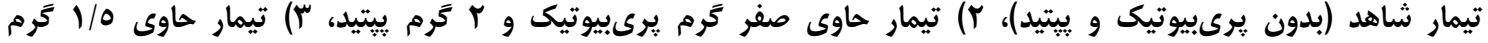

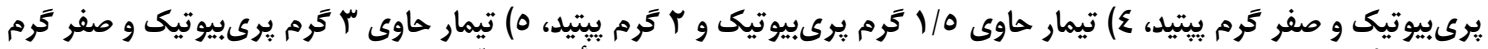

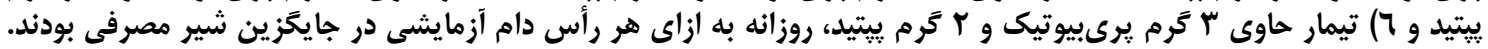

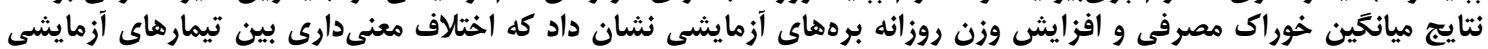

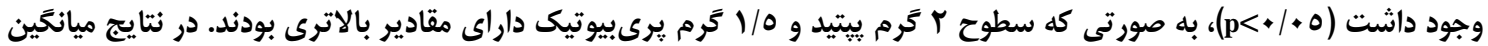

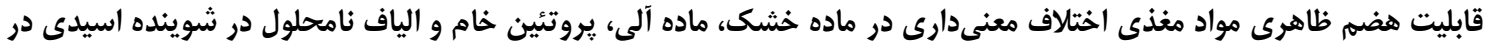

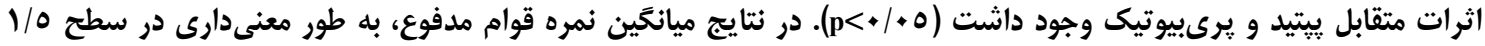

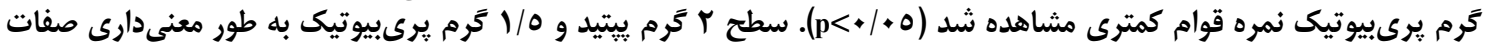

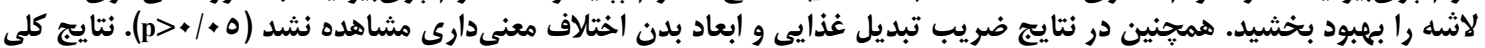

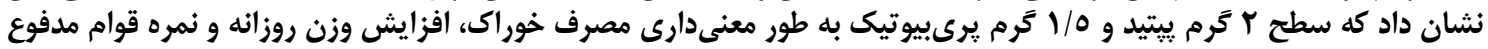

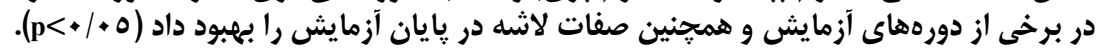

وازههاى كليدى: برههاى شيرخوار، يرىبيوتيك، يبتيد، عملكرد رشد، قابليت هضم

فرآيندهاى تخميرى به دست مى آينــد (عَّ). در زمـان تغذيسه

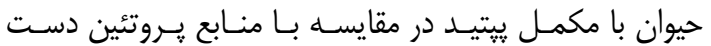

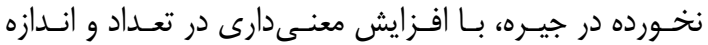

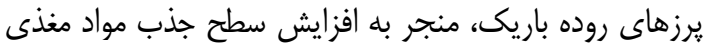

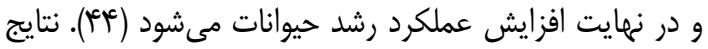

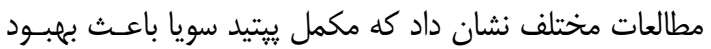

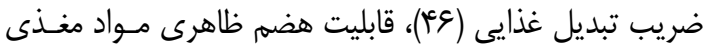

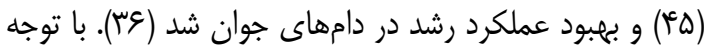

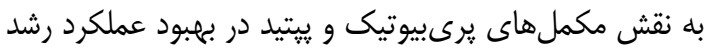

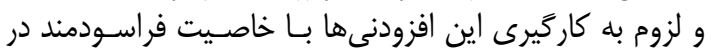

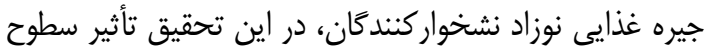

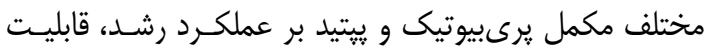

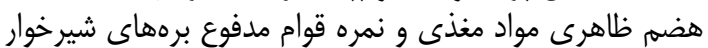
زل مورد بررسى قرار كرفت.

\section{مواد و روشها}

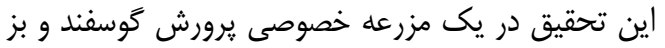

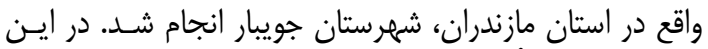

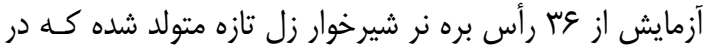

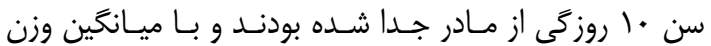

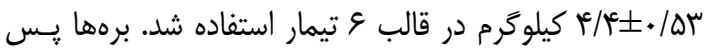

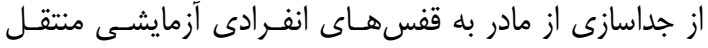

مقدمه

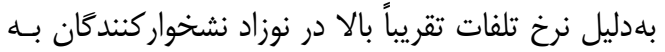

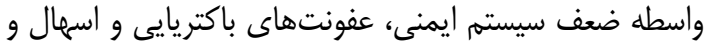

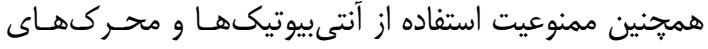

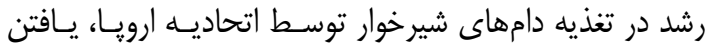

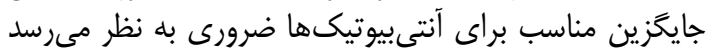

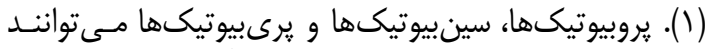

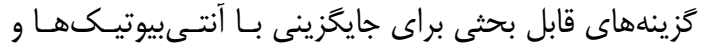

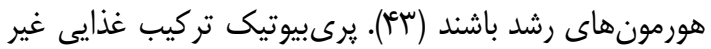

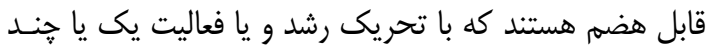

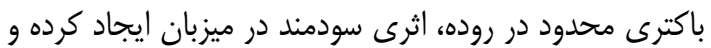

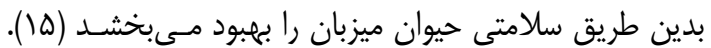

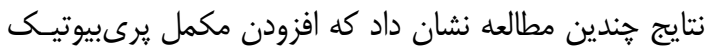

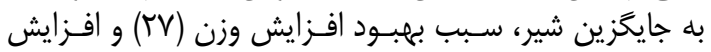

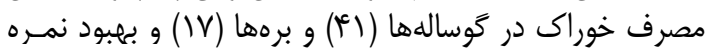

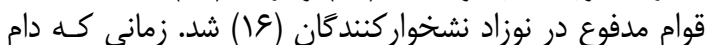

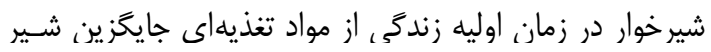

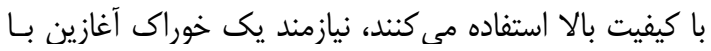

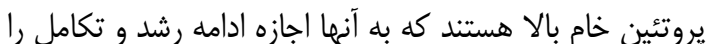

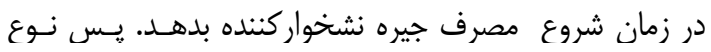

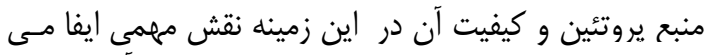

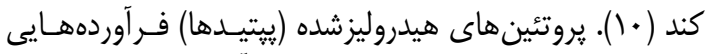

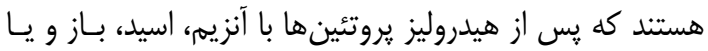


سويرناتانت حاصل با محلول ا مول اسيد كلريـــيـيك در

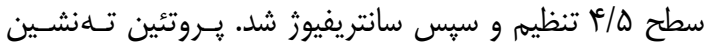

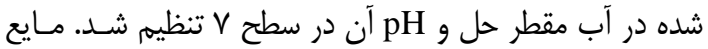

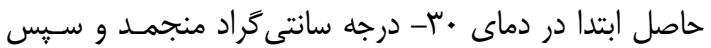

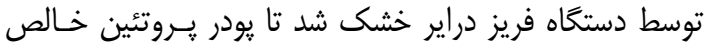

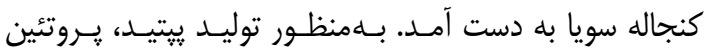

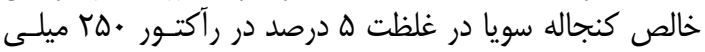

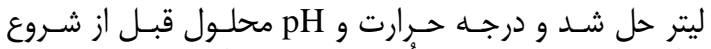

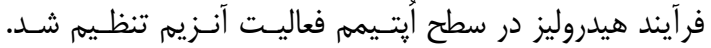

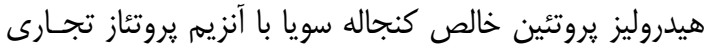

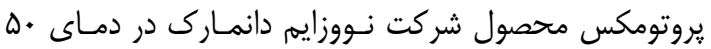

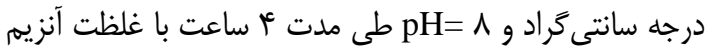

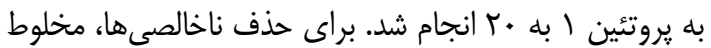

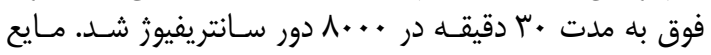

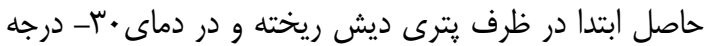

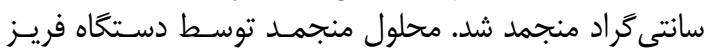

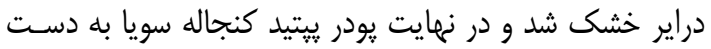

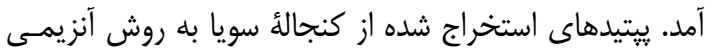

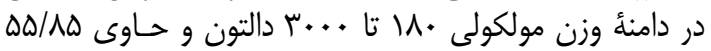

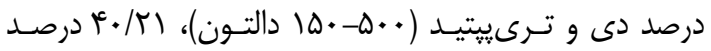

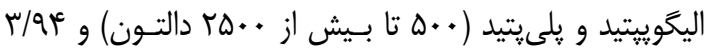

درصد اسيد آمينه (كمتر از •^1 دالتون) بودند (جدول ().

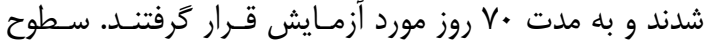

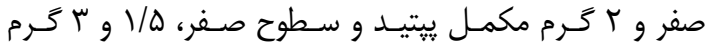

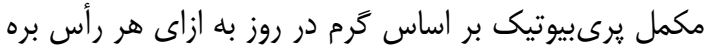

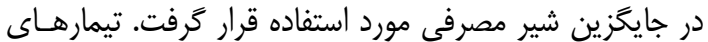

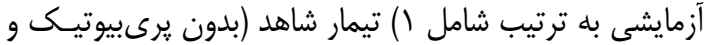

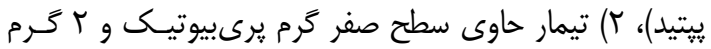

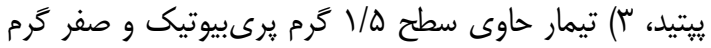

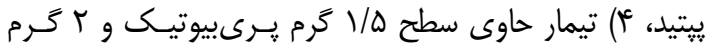

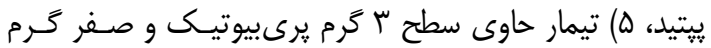

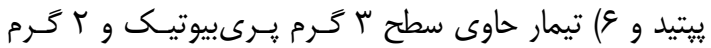

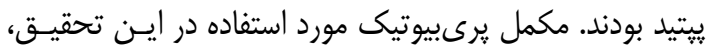

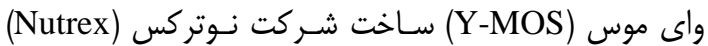

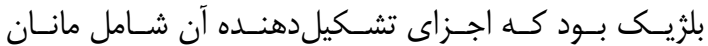

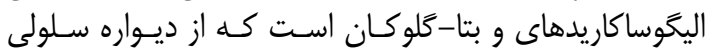

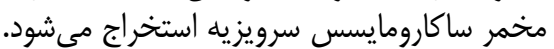

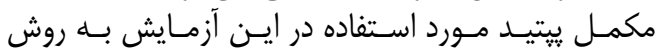

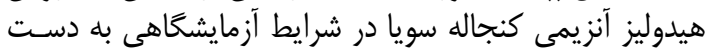

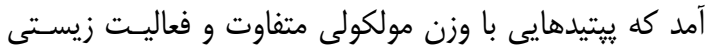

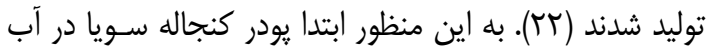

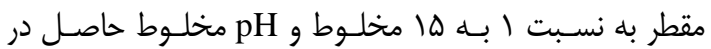

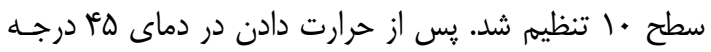

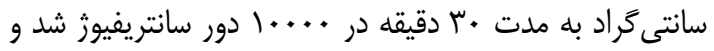

جدول ا- توزيع وزن مولكولى ييتيدهاى كنجاله سويا

Table 1. Molecular weight distribution of soybean peptide

\begin{tabular}{|c|c|}
\hline بيبيد (درصد) & وزن مولكولى (دالتون) \\
\hline.$/ 11$ & $>\mu \ldots$ \\
\hline.$/ q$. & $r \ldots-r_{n}$ \\
\hline $9 / 91$ & $1 \ldots-r \ldots$ \\
\hline$r q / \Delta q$ & $\Delta \cdots-1 \ldots$ \\
\hline$\Delta \Delta / \Delta \Delta$ & $1 \omega \cdot-\Delta \cdot$. \\
\hline$r / q F$ & $<1 \Lambda$. \\
\hline
\end{tabular}

كرفت. سيس در يايان هر روز مقدار باقىمانده خوراك تـوزين

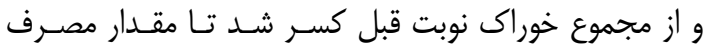

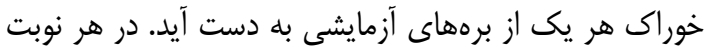

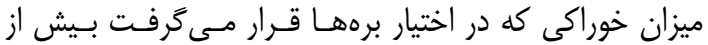

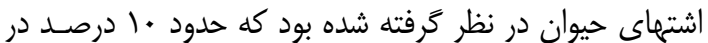

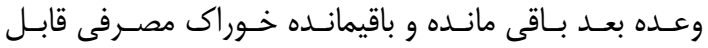

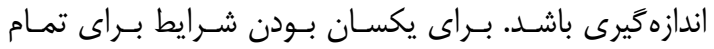

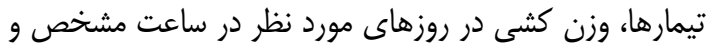

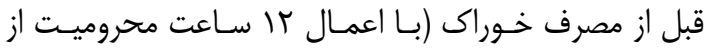

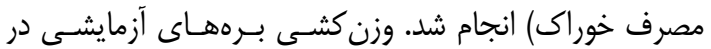

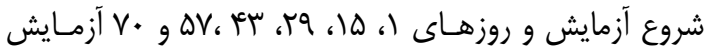

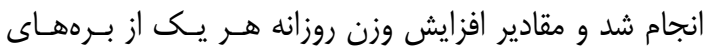

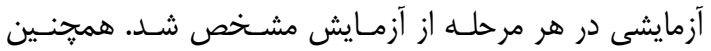

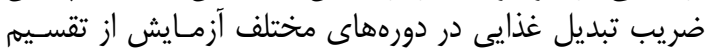

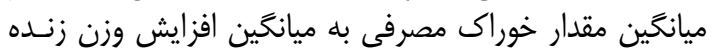
برههـاى هـر تيمـار محاسبه شد.
جايخزين شير مورد استفاده در اين تحقيـق، شـير خشـك

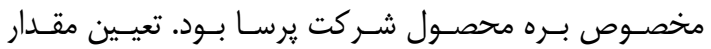

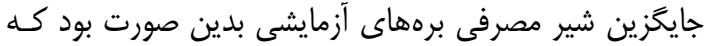

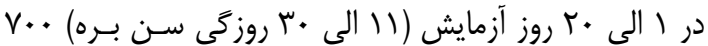

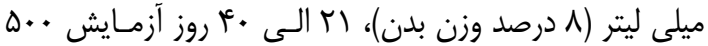

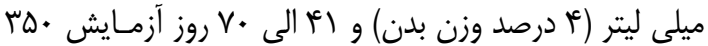

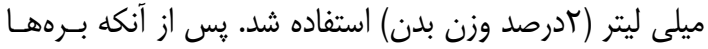

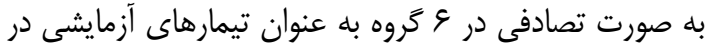

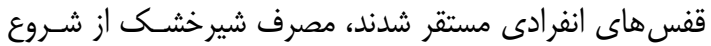

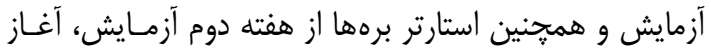

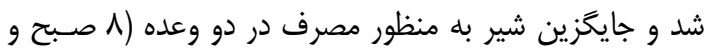

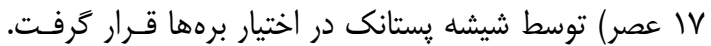

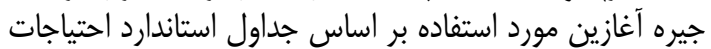

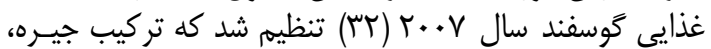

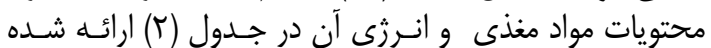

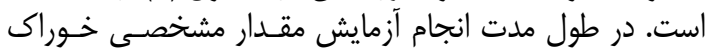

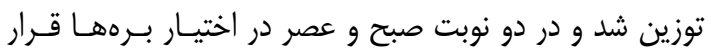


Table 2. Ingredients of the experimental diets and milk replacment

جدول r- اجزاى تشكيلدهنده جيرههاى آزمايشى و جايخزين شير

\begin{tabular}{|c|c|c|c|}
\hline مقدار در هر كيلوكَرم جايكزين شير (درصد) & تركيبات جايكزين شير & مقدار در جيره & ماده خوراكى (درصد) \\
\hline tr & بروتئين & ra & دانه ذرت \\
\hline r. & 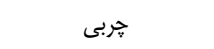 & r. & 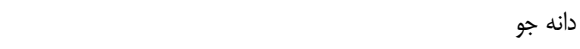 \\
\hline r. & ل اكتوز & r. & كنجاله سويا \\
\hline.$/ 9$ & 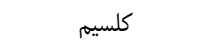 & r & ملاس קغندر قند \\
\hline$\cdot / V$ & فسفر & $\Delta / \Delta$ & كنجاله ينبه دانه \\
\hline $1 / 8$ & يتاسيم & $1 / \Delta$ & روغن نباتى \\
\hline$r / \Delta$ & ليزين & $r / \Lambda$ & سبوس گَندم \\
\hline$\cdot / V$ & 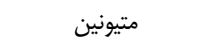 & $\cdot / r$ & نمك \\
\hline 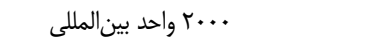 & A ويتامين &.$/ \Delta$ & 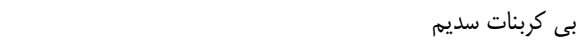 \\
\hline 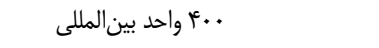 & Dيتامين D D D D & $\cdot / \Delta$ & مكمل معدنى+ ويتامينى ' \\
\hline 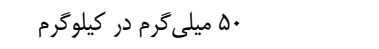 & E ت Eيتامين & 1 & كربنات كلسيم \\
\hline • و واحد بينالمللى & 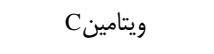 & & تركيب شيميايى جيره \\
\hline Vيلى كرم در كيلوكَرم V. & آهن & $r / r$ & انرزى قابل قابل سوخت و ساز (مكاكالرى در كيلوكرم ماده خشك) \\
\hline r ميلى گَرم در كيلوَّرم & 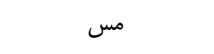 & M & يروتئين خام (٪) \\
\hline 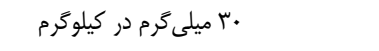 & روى & $\cdot / V$ & كلسيم (\%) \\
\hline ع/ • ميلى گرم در كيلوكرم & 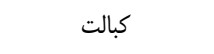 &.$/ 4 \wedge$ & 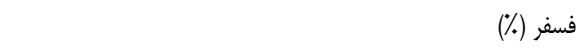 \\
\hline ه/ • ميلى گرم در كيلوكرم & يد &.$/ 10$ & 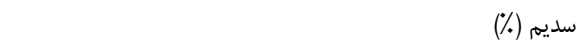 \\
\hline 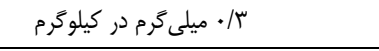 & 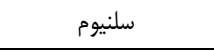 & & \\
\hline
\end{tabular}

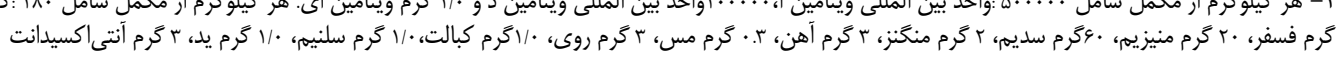

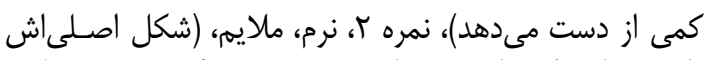

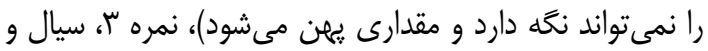

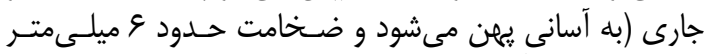
دارد) و نمره أ، آبكى (قوام مايع و ترشحى ديى دارد) بود.

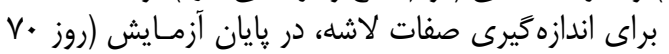

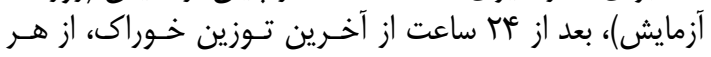

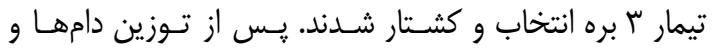

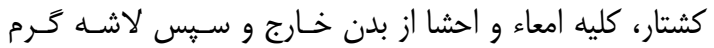

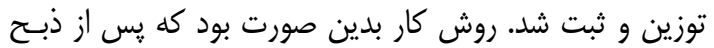

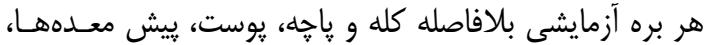

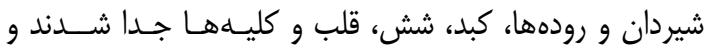

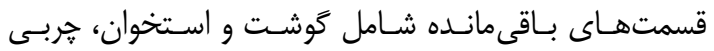

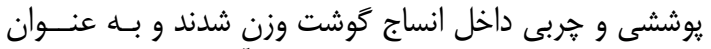

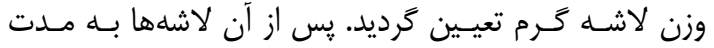

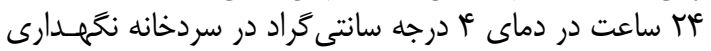

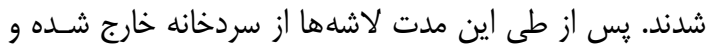

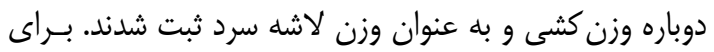

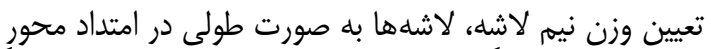

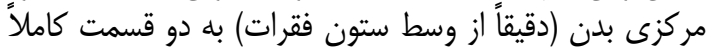

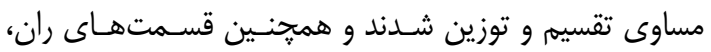

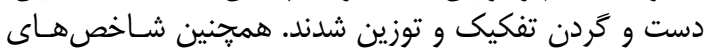

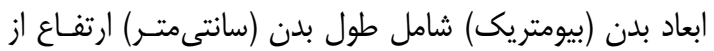

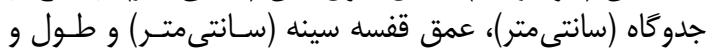
عرض كيل (سانتىمتر) نيز اندازهگيرى شدى شد.
اندازهزيرى قابليت هضم ظاهرى ماده خشك، ماده آلى و

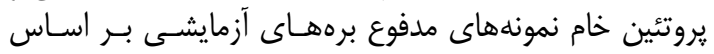

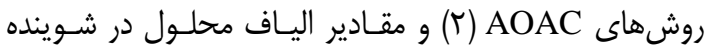

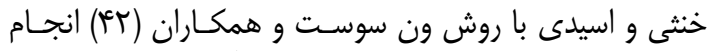

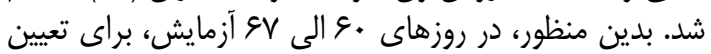

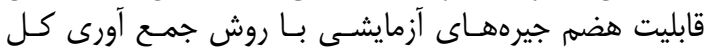

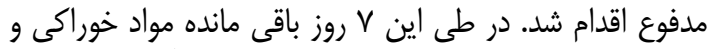

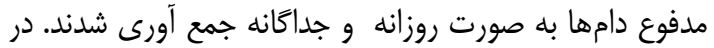

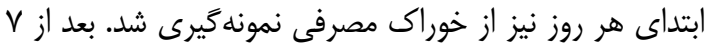

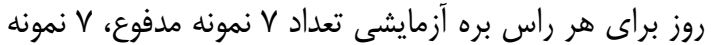

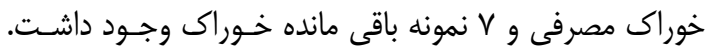

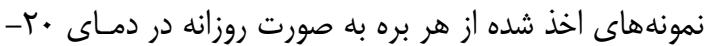

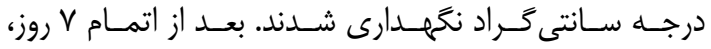

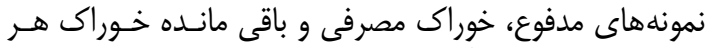

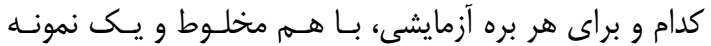

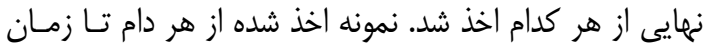

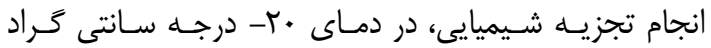

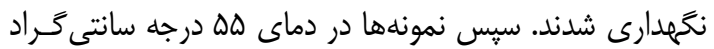

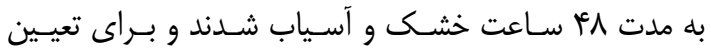

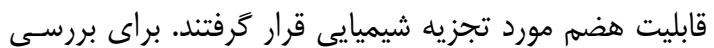

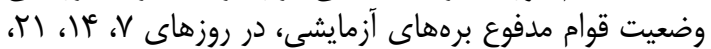

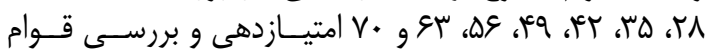

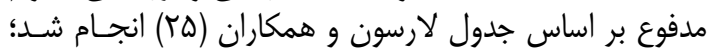

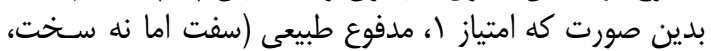

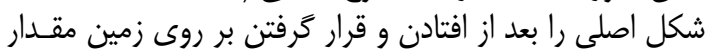


مقايسه ميانكين تيمارهاى آزمايشى با استفاده از آزمون حند إندام دامنهاى دانكن در سطح احتمال هـ/ • انجام شد.

نتايج و بحث مصان مصبر

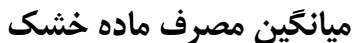

نتايج ميانخين ماده خشك ماده خشى مصرفى برههـاى آزمايشـى در

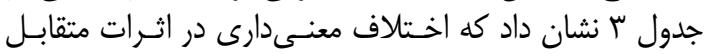

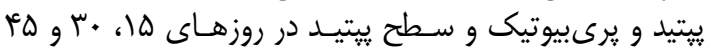

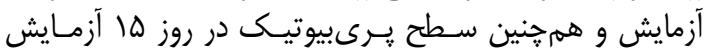

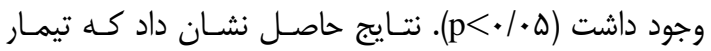

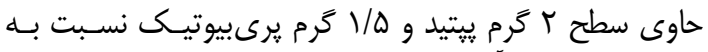

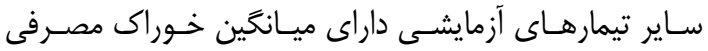

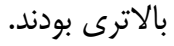

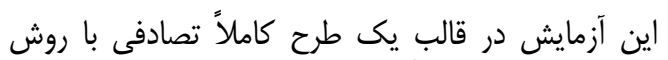

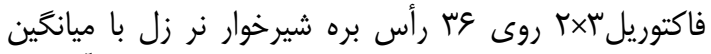

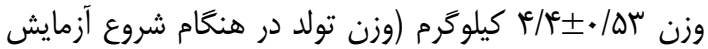

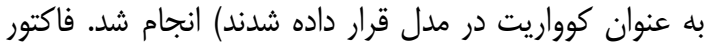

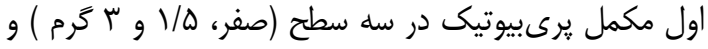

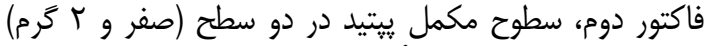

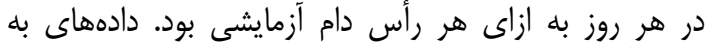

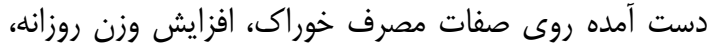

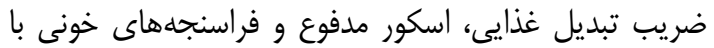

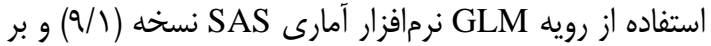
اساس مدل Yijk= شدند (Nب) كه در اين فرمول

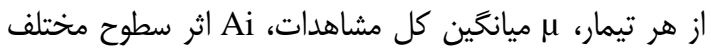

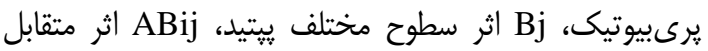

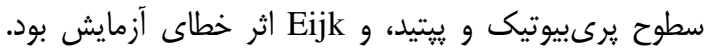

Table 3. The mean feed intake of lambs during different experimental periods (g)

جدول ب- ميانگين خوراك مصرفى برهها در طول دورههاى مختلف آزمايش (كرم)

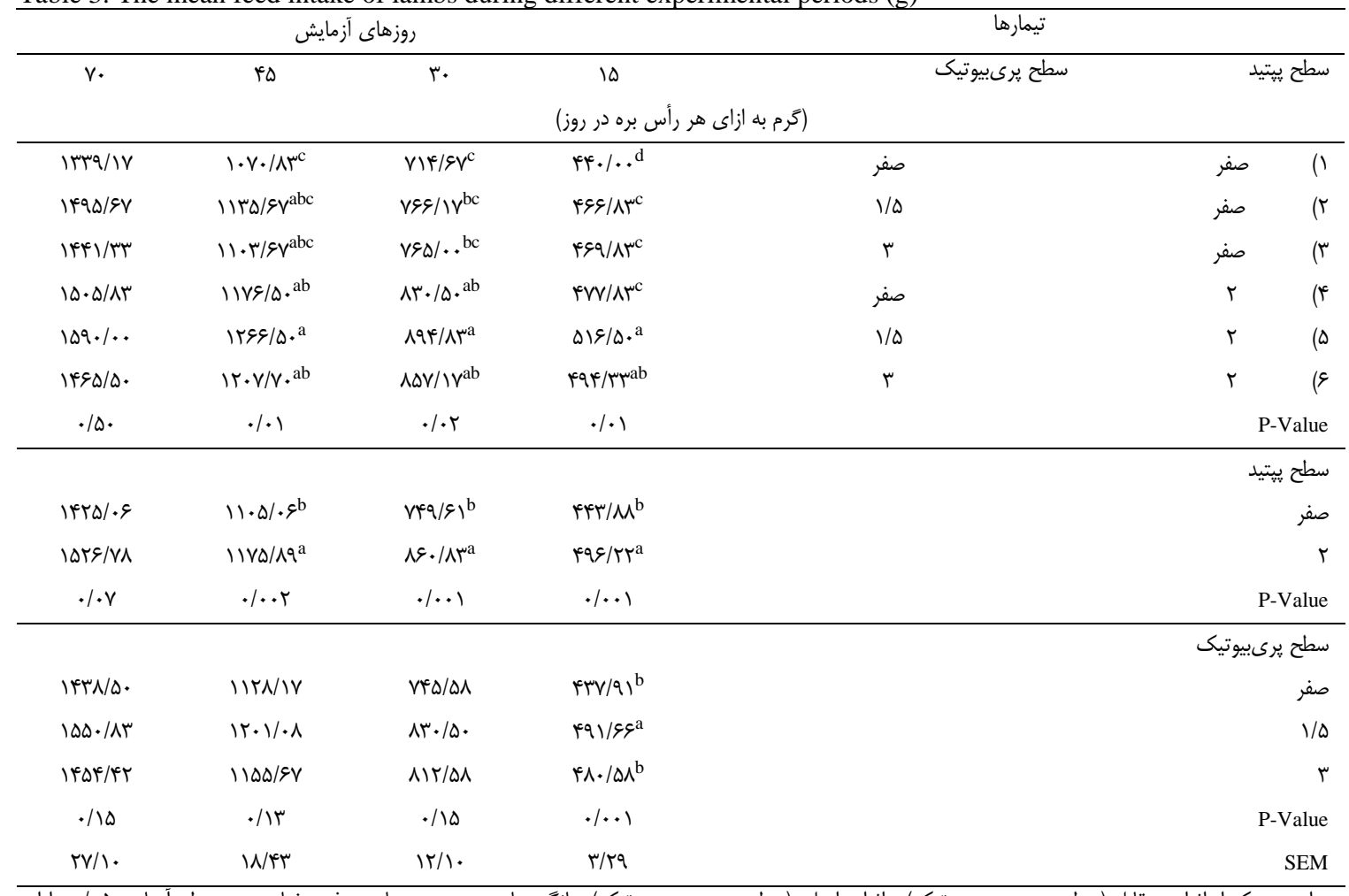

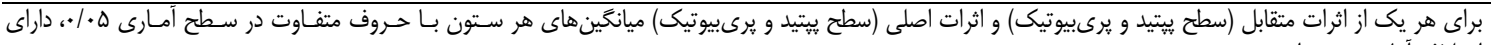
اختلاف آمارى معنى دارى هستند. SEM

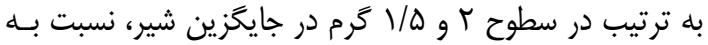

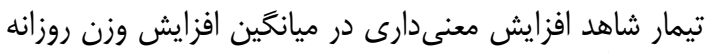

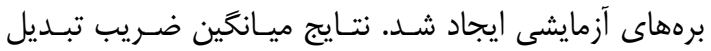

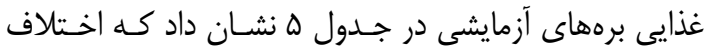

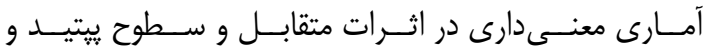
يرىبيوتيك بين تيمارهاى آزمايشى وجود نداشت

P-Value

ميانگين افزايش وزن روزانه

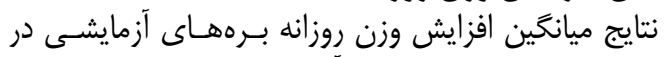

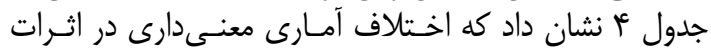

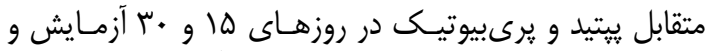

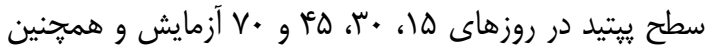

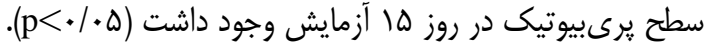

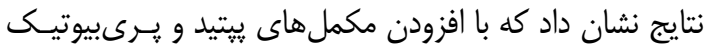


جدول أ- ميانگين افزايش وزن روزانه برهها در طول دورههاى مختلف آزمايش (گرم) Table 4. The mean daily weight gain of lambs during different experimental periods (g)

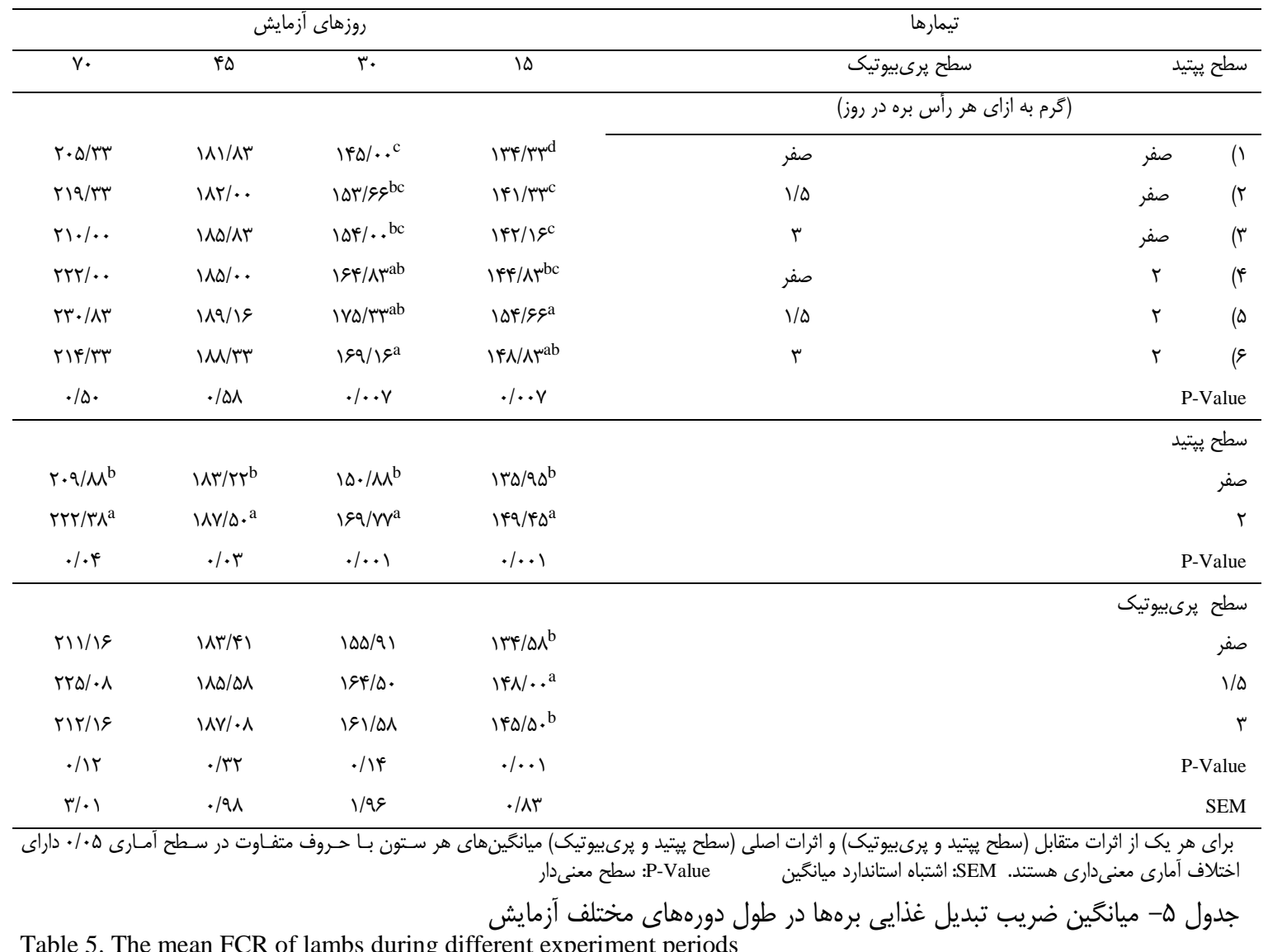

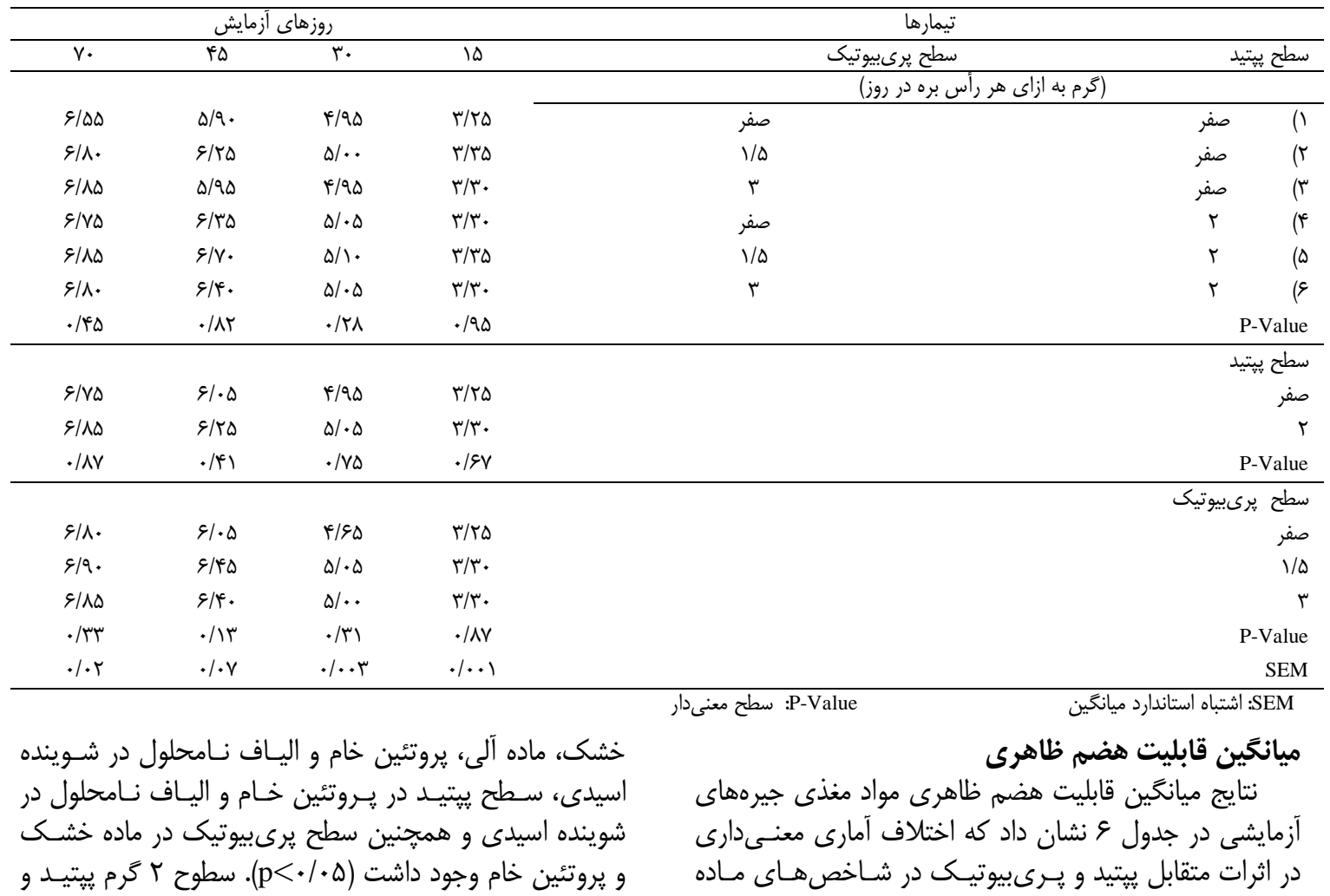


برههاى آزمايشى به طور معنسى دارى برخى از شـاخصهـاى قابليت هضم مواد مغذى را بهبود داد.

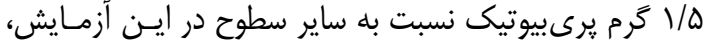

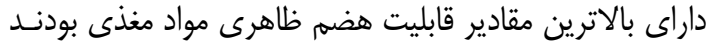

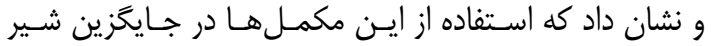

جدول 9- ميانكَين قابليت هضم ظاهرى مواد مغذى جيرههاى آزمايشى (درصد) Table 6. The mean apparent digestibility nutrients of experimental diets (\%)

\begin{tabular}{|c|c|c|c|c|c|c|c|}
\hline \multicolumn{5}{|c|}{ شاخصها } & \multicolumn{3}{|c|}{ تيمارها } \\
\hline شوينده اسيدى داف & شالياف نامحلول در & يروتئين خام & ماده آلى & ماده خشك & سطح برى بيوتيك & سطح يِيتيد & \\
\hline & & & & & (ه در روز) & & \\
\hline$\Delta \cdot / q \gamma^{b}$ & $\Delta s / \Delta \Lambda$ & $q \pi / a g^{b}$ & $g r^{f} / q^{b}$ & $9 \cdot \mid \Lambda e^{c}$ & صفر & صفر & () \\
\hline$\Delta r / T^{a b}$ & $\Delta V / V \Psi$ & $s+/ \backslash \lambda^{b}$ & $\Leftrightarrow \& / \Delta \Delta^{\mathrm{ab}}$ & s)/A.c & $1 / \Delta$ & صفر & (r \\
\hline$\Delta r / \& c^{a b}$ & $\Delta V / N G$ & $\varepsilon \& / q$ mab & $G \Delta / q^{a b}$ & gs/Arab & r & صفر & (r \\
\hline$\Delta T / / V^{a b}$ & سN/F & $s \Delta / V^{\mathrm{ab}}$ & $\varepsilon \Delta / M^{a b}$ & $94 / 9 \Delta^{\mathrm{ab}}$ & صفر & r & (i \\
\hline$\Delta r / r \cdot{ }^{a}$ & $\Delta q / \backslash 9$ & $\$ 9 / \propto r^{\mathrm{a}}$ & $9 N / 11^{\mathrm{a}}$ & $99 / \Delta \Lambda^{a}$ & $1 / 0$ & $r$ & $(\Delta$ \\
\hline$\Delta f / / V^{a}$ & $\Delta q / \Psi_{q}$ & $9 q / \cdot r a$ & $s N / q^{a}$ & $\varepsilon \mathcal{N} / \varphi^{\mathrm{a}}$ & r & $r$ & (द \\
\hline.$/ . r$ & $\cdot / \mathrm{V}^{\mathrm{C}}$ & .1 .4 &.$/ .4$ & .1 .4 & & & \\
\hline & & & & & & & \\
\hline$\Delta I / \Lambda I^{b}$ & $\Delta V / . \varphi$ & $s x^{c} / q^{b}$ & 991.4 & $g F / \Delta r$ & & & صفر \\
\hline$\Delta \Gamma / \Delta \Delta^{\mathrm{a}}$ & $\Delta N / V T$ & $9 N / V^{r^{a}}$ & $9 \mathrm{~V} / 1$. & G & & & $r$ \\
\hline $.1 . r$ & $.1 / 0$ & $\%$. .r & $\cdot / T V$ & سז/. & & & \\
\hline & & & & & & كبيوتيك & \\
\hline DI/AV & $\Delta v / r q$ & $\bar{s} / \mu \Delta^{b}$ & $9 \Delta / r \Delta$ & GT/rrb & & & صفر \\
\hline$\Delta T / V Q$ & $\Delta N / I V$ & $9 N / 9 \Delta^{\mathrm{a}}$ & SV/TA & $Q V / \Delta q^{a}$ & & & $1 / 0$ \\
\hline DT/FT & $\Delta N / F F^{C}$ & $9 \mathrm{~V} / \mathrm{l} \cdot \mathrm{a}$ & $98 / 90$ & $g V / r \varphi^{a}$ & & & r \\
\hline$\cdot / r$. & $\cdot|\wedge|$ &.$/ . r$ & سו/. & .1 .4 & & & alue \\
\hline$\cdot / \mu$. & $\cdot / \Delta \Delta$ & . &.$/ 4$ & .199 & & & SEM \\
\hline
\end{tabular}

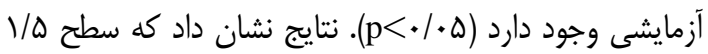

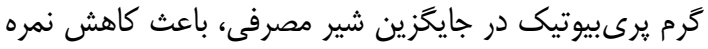

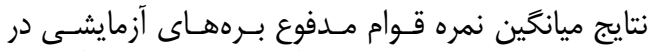

Table 7. The mean fecal score of lambs during different experiment periods

\begin{tabular}{|c|c|c|c|c|c|}
\hline \multicolumn{4}{|c|}{ روزهاى آزمايش } & \multicolumn{2}{|c|}{ تيمارها } \\
\hline v. & in & $r$. & 10 & سطح برى بيوتيك (صفر، ه/ و ؟r) & سطح ييتيد (صفر و r) \\
\hline & & & & \multicolumn{2}{|c|}{ (كرم به ازاى هر رأس بره در روز) } \\
\hline l/AF & l/A & $r / 99$ & $r / . \cdot$ & صفر & صفر \\
\hline $1 / 99$ & זr/ & $r / l g$ & $1 / 99$ & $1 / \Delta$ & صفر \\
\hline$r / \Lambda Q$ & $1 / \Lambda \mu$ & $r / \ell \varepsilon$ & $r / \cdot$ & r & صفر \\
\hline I/Ar & $1 / 14$ & سז/T & $r / 19$ & صفر & r \\
\hline 1/a. & $1 / \omega$ & $1 / 99$ & س & $1 / \Delta$ & r \\
\hline سז/1 & זr/1 & $1 / \Delta$. & سז/1 & r & r \\
\hline 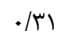 & ret & $\cdot / 19$ & $\cdot / \mu$ & & P-Value \\
\hline & & & & & سطح يِيتيد \\
\hline I/AV & $1 / 99$ & سז/ץ & $1 / M$ & & \multirow{3}{*}{$\begin{array}{r}\text { صفر } \\
\text { P-Value }\end{array}$} \\
\hline $1 / \Delta \Delta$ & $1 / \Delta \Delta$ & I/A & $1 / 91$ & & \\
\hline.$/ 19$ &.$/ 91$ & .1 .9 & $\cdot / \pi \mid$ & & \\
\hline & & & & & سطح برى بيوتيك \\
\hline l/A & $1 / \wedge r$ & $r / \Delta$ & $r / \cdot \Lambda^{a}$ & & صفر \\
\hline $1 / \Delta \Lambda$ & $1 / 41$ & $1 / 91$ & $1 / \Delta \cdot b$ & & $1 / \Delta$ \\
\hline $1 / V \Delta$ & $1 / \Delta \Lambda$ & l/^r & $1 / 99^{b}$ & & r \\
\hline.$/ 8 \mathrm{~V}$ & $\cdot / \Gamma \cdot$ & $. / 1)^{4}$ & $.1 \cdot e^{\mathrm{c}}$ & & P-Value \\
\hline.$/ 14$ & $\cdot / 1$ & $\cdot / 10$ &.$/ 11$ & & SEM \\
\hline
\end{tabular}




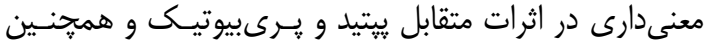

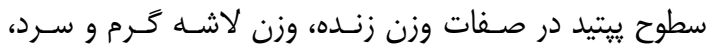

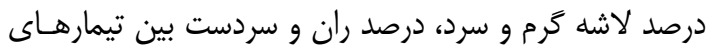

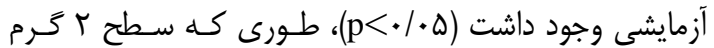

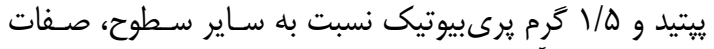
لاشه برههاى أزمايشى را برمبود بيود بخشيد.
صفات ابعاد بدن

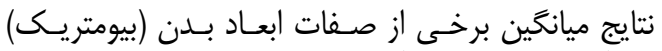

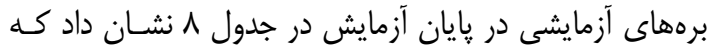

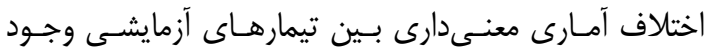
نداشت.

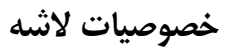

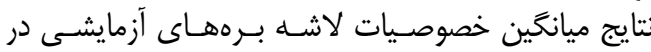

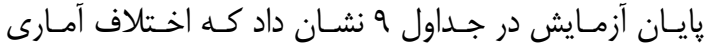

جدول ^- ميانگين برخى صفات بيومتريك برهها در بايان آزمايش (سانتىمتر) Table 8. The mean some biometric traits of lambs in the end of the experiment (cm)

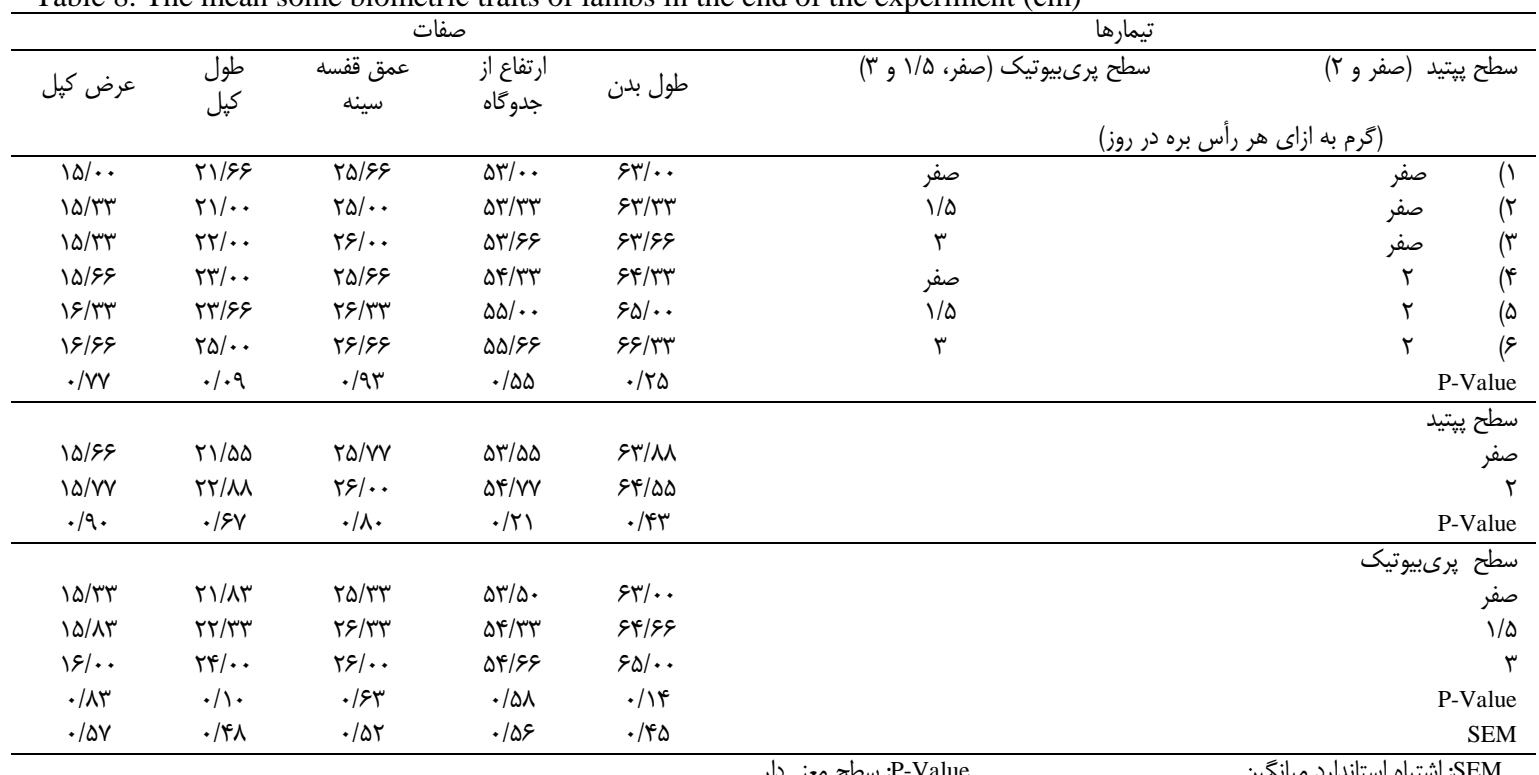

جدول 9- ميانكين برخى از صفات لاشه برهها در پايان آزمايش

Table 9. The mean some carcass traits of lambs in the end of the experiment

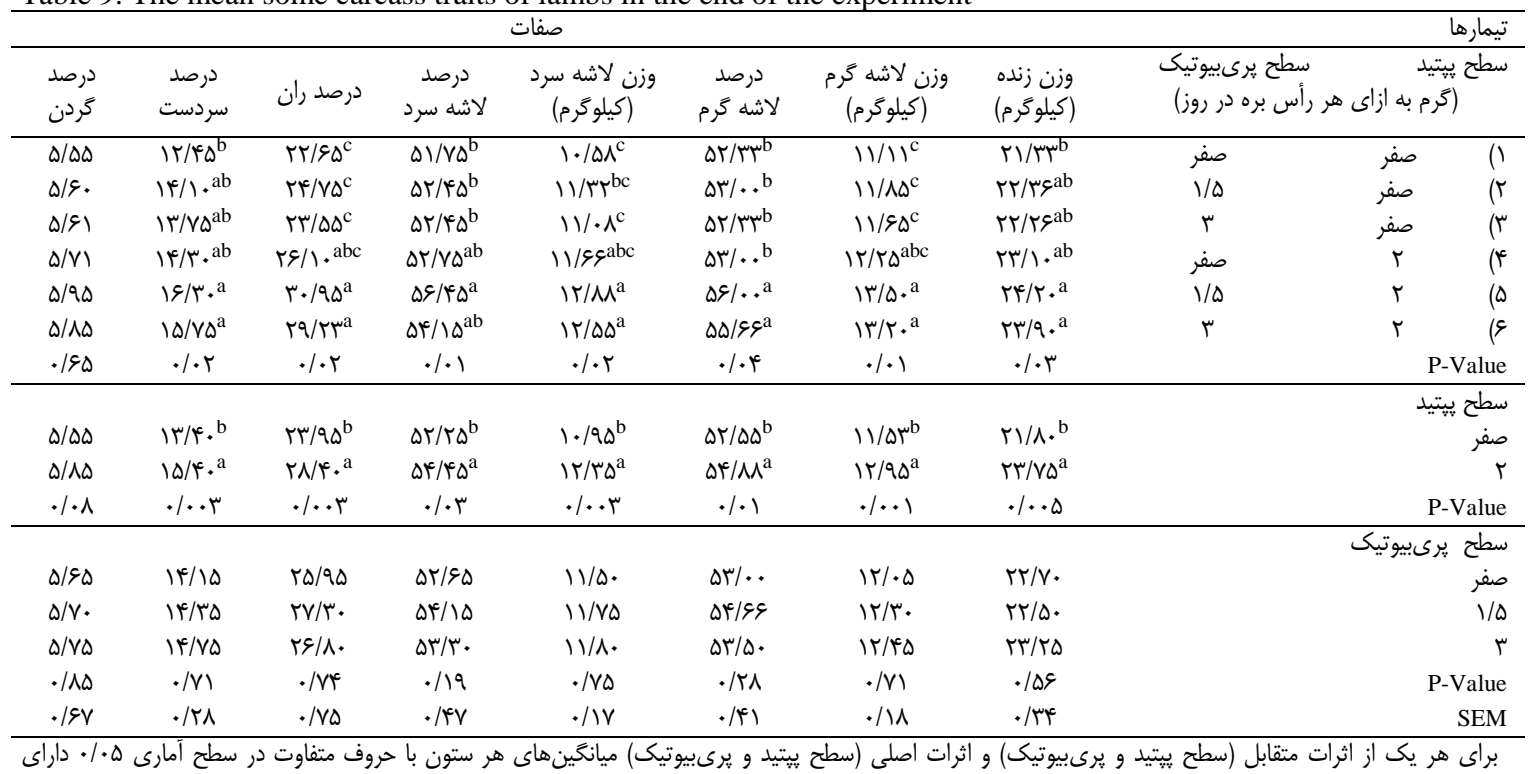


بيشترين مصرف خوراك و يايينترين ضـريب تبـديل غـذايى نسبت به ساير جيرهها بودند.

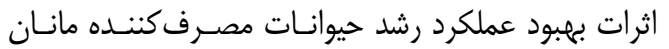

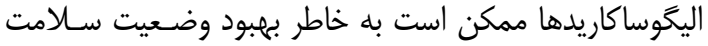

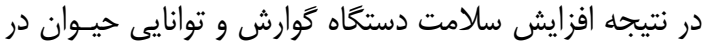

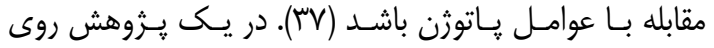

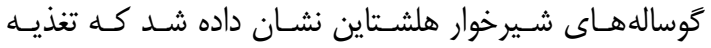

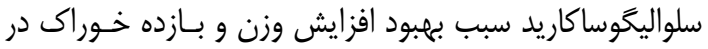

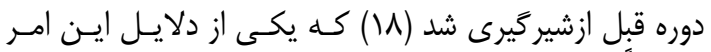

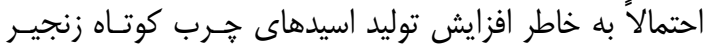

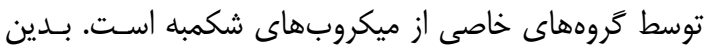

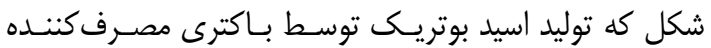

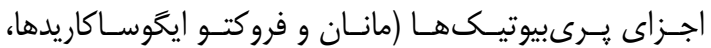

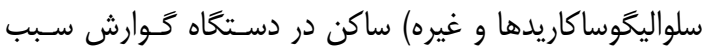

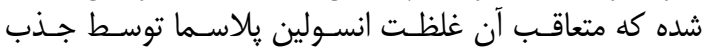

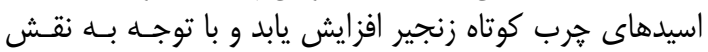

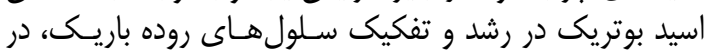

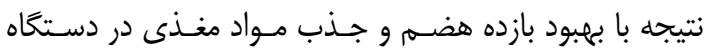

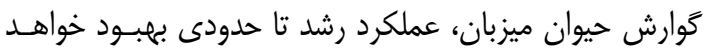

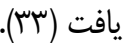

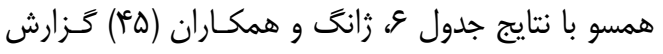

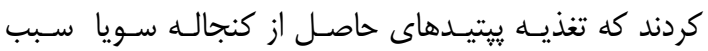

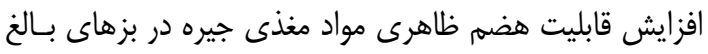

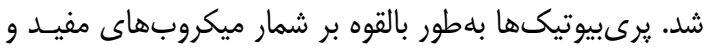

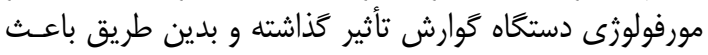

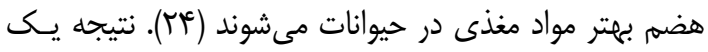

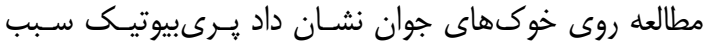

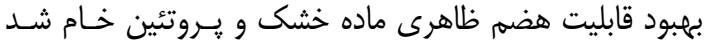

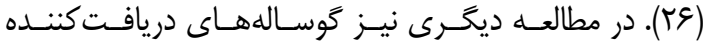

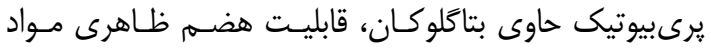

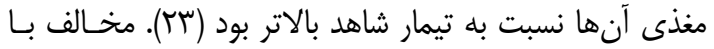

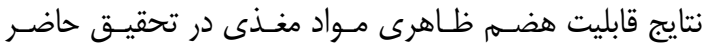

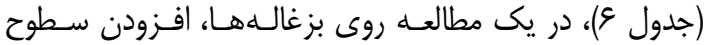

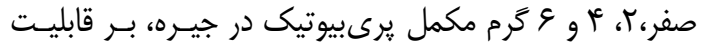

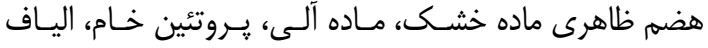

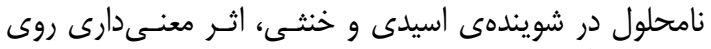

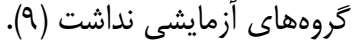

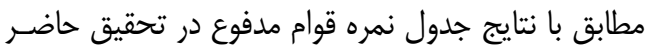

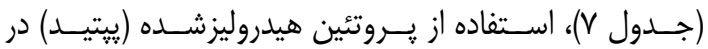

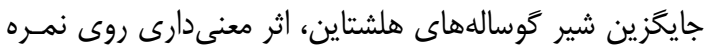

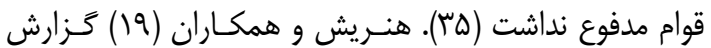

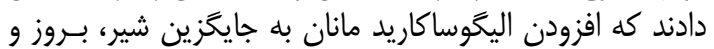

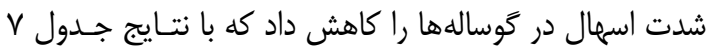

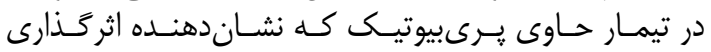

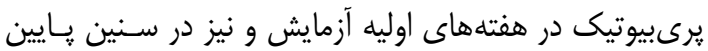

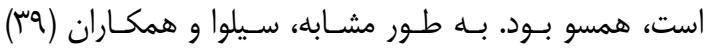

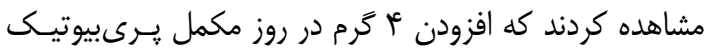

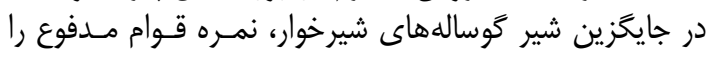

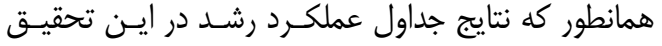

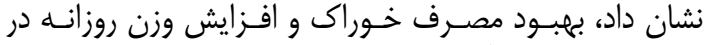

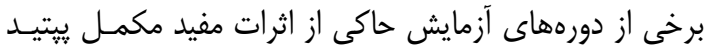

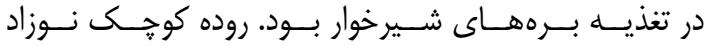

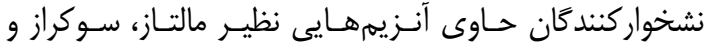

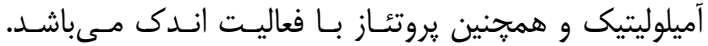

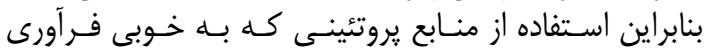

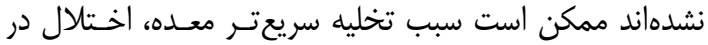

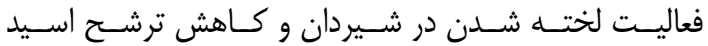

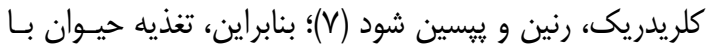

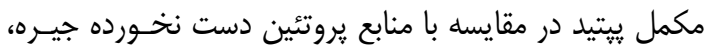

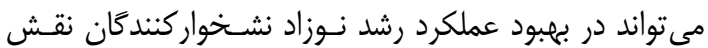

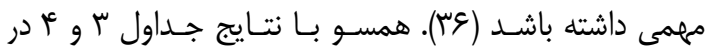

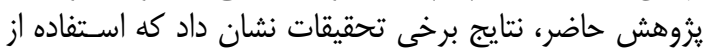

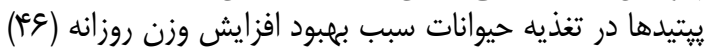

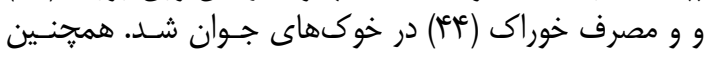

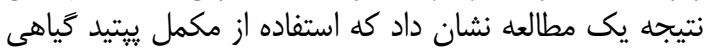

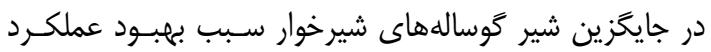

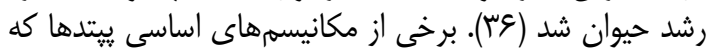

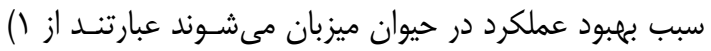

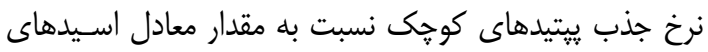

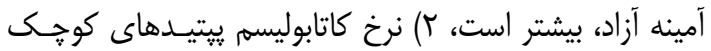

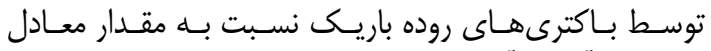

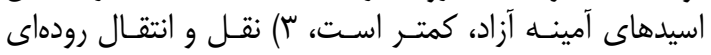

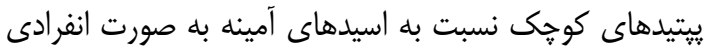

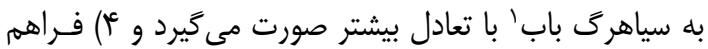

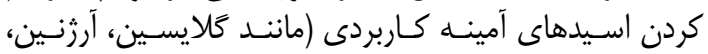

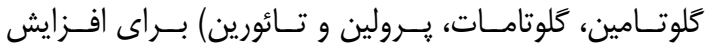

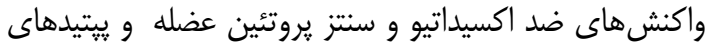

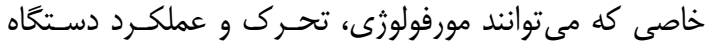

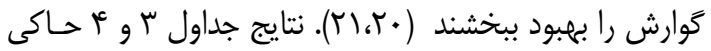

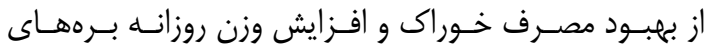

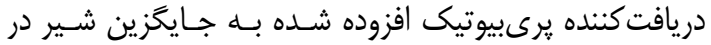

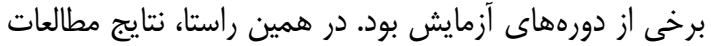

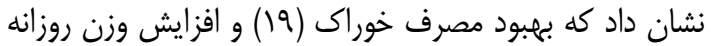

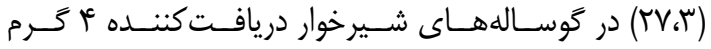

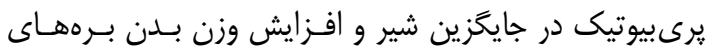

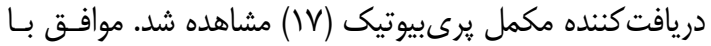

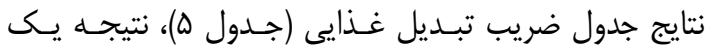

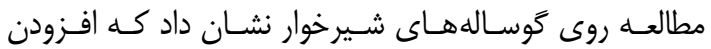

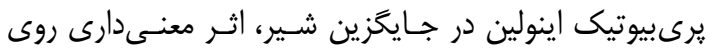

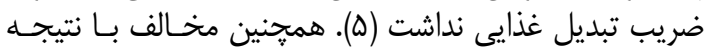

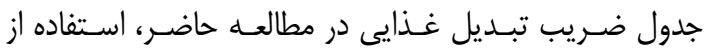

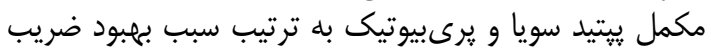

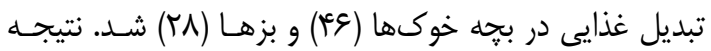

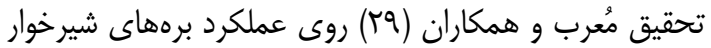

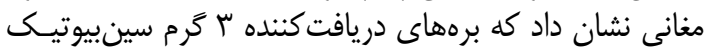

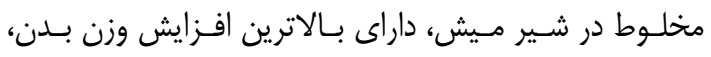




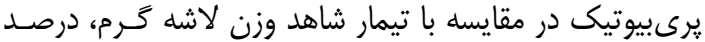

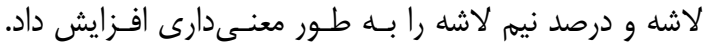

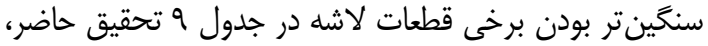

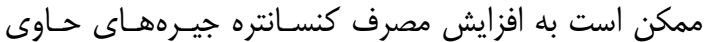

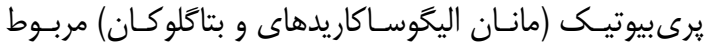

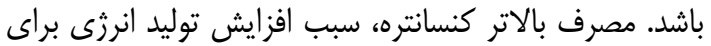

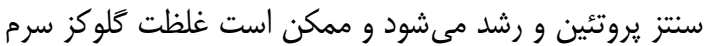

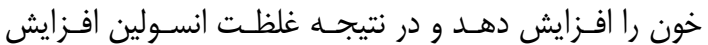

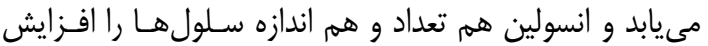

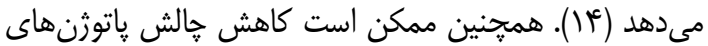

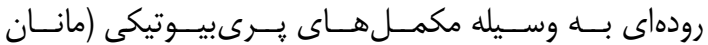

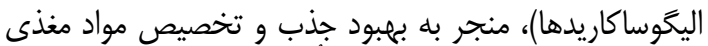

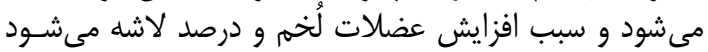

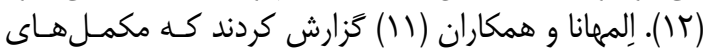

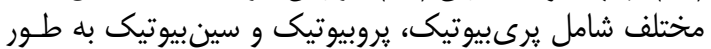

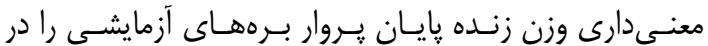

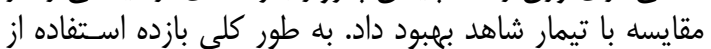

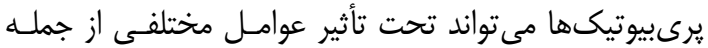

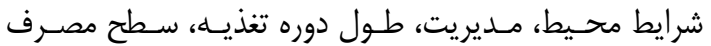

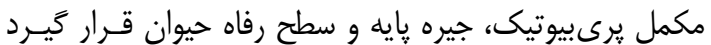

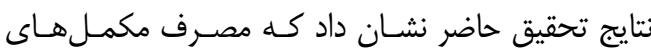

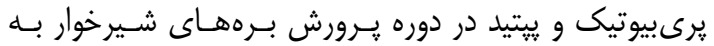

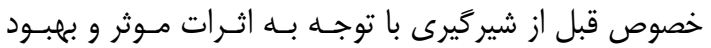

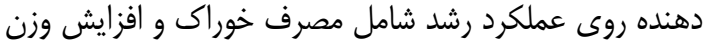

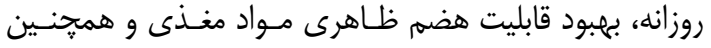

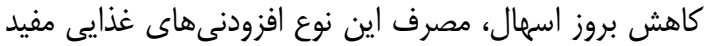

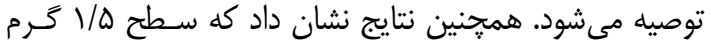

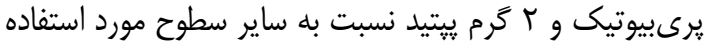
داراى عملكرد بهترى در صفات مورد مطالعه بود.
تنها در هفته اول آزمايش بهبــود داد. در مطالعـهـ قـوش و و

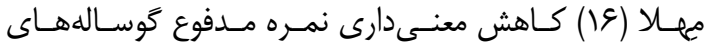

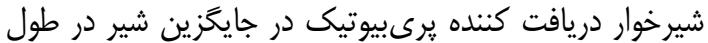

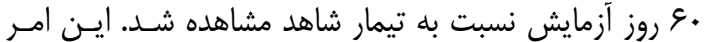

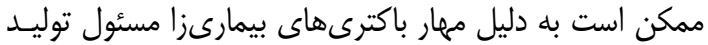

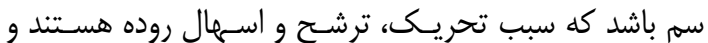

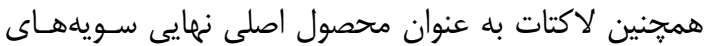

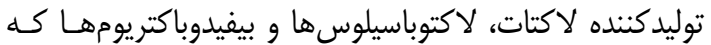

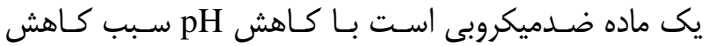

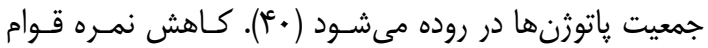

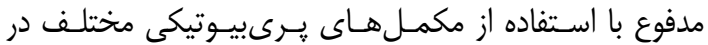

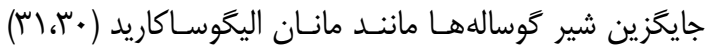

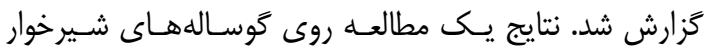

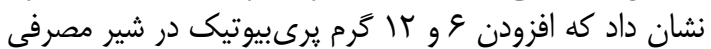

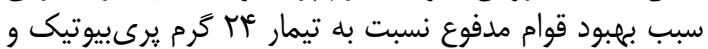

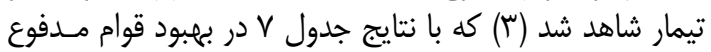

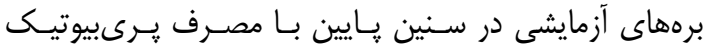
مطابقت داشت.

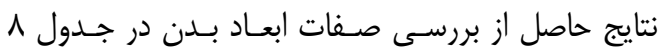

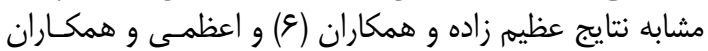

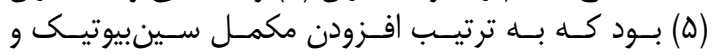

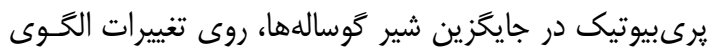

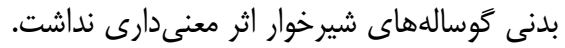

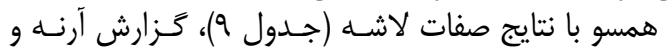

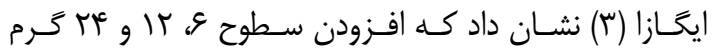

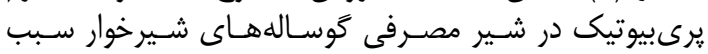

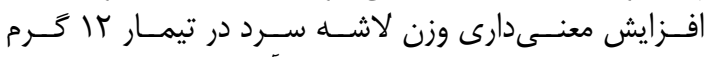

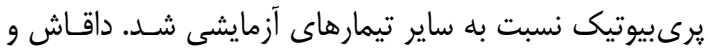

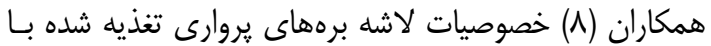

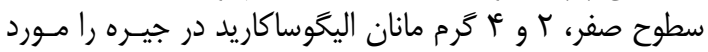

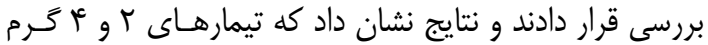

منابع

1. Anadón, A., M.R. Martínez-Larrañaga and V. Castellano. 2012. Regulatory aspects for the drugs and chemicals used in food-producing animals in the European Union. In Veterinary Toxicology: Basic and Clinical Principles. (Second Edition), 135-155.

2. AOAC. 1990. Official Methods of Analysis 15th ed. AOAC, Arlington, VA.

3. Ārne, A. and A.Ilgaža. 2016. Different dose inulin feeding effect on calf digestion canal state and development. ReseaRch foR RuRal Development, 1.

4. Attalah, G.Y. 1988. Studies on fatting cross breed lambs. M.Sc. Thesis, Fac. of Agric., Al-Azhar University, Cairo, Egypt.

5. Azami, M.H., A. Tahmasbi, A. Valikhani and A. Naserian. 2017. Evaluation of performance, blood parameters and microbial population of feces in suckling Holstein calves fed with supplemented milk by inulin prebiotic. Journal of Ruminant Research, 5: 111-130 (In Persian).

6. Azimzadeh, V., A. Asadi Alamoti, A.A. Khadem, M. Bagheri Varzaneh and J.M. Moradi. 2016. Effects of Supplementation of a Symbiotic Product on Growth Performance and Health of Holstein Calves. Research on Animal Production, 12: 105-114 (In Persian).

7. Caugant, I., R. Toullec, M. Formal, P. Guilloteau and L. Savoie. 1993. Digestibility and amino acid composition of digesta at the end of the ileum in preruminant calves fed soyabean protein. Reproduction Nutrition Development, 33: 335-347.

8. Daghash, M.W., M.A. El-Ati, F.M. Allam and S.F. Abbas. 2014. Carcass characteristics of Saidi rams fed mannan oligosaccharide supplemented diet. Assiut Journal of Agricultural Sciences, 45: 13-24.

9. Dare-zereshkipour, M., K.H. Parsaei Mehr, S. Hoseinzadeh and P. Farhomand. 2013. The effects different levels of prebiotic supplementation (A-Max) on digestibility and some biochemical 
parameters of serum of native kids of West Azarbaijan province. Journal of Pathology, Veterinary Clinic, 7: 314-351 (In Persian).

10. Drackley, J.K., K.S. Bartlett and R.M. Blome. 2003. Protein content of milk replacers and calf starters for replacement calves. University of Illinois Extension. Illini dairy net.(Online): http://www. livestocktrail. uiuc. edu/dairynet/paperDisplay. cfma

11. El-Mehanna, S.F., M.M. Abdelsalam, N.M. Hashem, K.E.M. El-Azrak, M.M. Mansour and M.M. Zeitoun. 2017. Relevance of probiotic, prebiotic and synbiotic supplementations on hematobiochemical parameters, metabolic hormones, biometric measurements and carcass characteristics of sub-tropical Noemi lambs. International Journal of Animal Research, 1: 10-22.

12. Ferket, P.R. 2004. Alternatives to antibiotics in poultry production: responses, practical experience and recommendations. Nutritional Biotechnology in the Feed and Food Industries, 57-67.

13. Gaggìa, F., P. Mattarelli and B. Biavati. 2010. Probiotics and prebiotics in animal feeding for safe food production. International journal of food microbiology, 141: 15-28.

14. Gardner, H.G. and P.L. Kaye. 1991. Insulin increases cell numbers and morphological development in mouse pre-implantation embryos in vitro. Reproduction, Fertility and Development, 3: 79-91.

15. Gibson, G.R. and M.B. Roberfroid. 1995. Dietary modulation of the colonic microbiota: Introducing the concept of prebiotics. Journal Nutrition, 125: 1401-1412.

16. Ghosh, S. and R.K. Mehla. 2012. Influence of dietary supplementation of prebiotics (mannanoligosaccharide) on the performance of crossbred calves. Trop. Animal Health Products, 44: 617-622.

17. Hady, M.M., R.A. EL-Banna, H.M. Teleb and R.A. Shimaa. 2012. Evaluation of Mannanoligosaccharide (Bio-Mos®) and Esterified Glucomannan (MTB-100®) Dietary Supplementation on Growth Performance, Serum Parameters and Rumen Ecology of Barki Lambs under Egyptian Environment. APCBEE Procedia, 4: 158-162.

18. Hasunuma, T., K. Kawashima, H. Nakayama, T. Murakami, H. Kanagawa, T. Ishii, K. Akiyama, K. Yasuda, F. Terada and S. Kushibiki. 2011. Effect of cellooligosaccharide or synbiotic feeding on growth performance, fecal condition and hormone concentrations in Holstein calves. Animal Science Journal, 82: 543-548.

19. Heinrichs, A.J., C.M. Jones and B.S. Heinrichs. 2003. Effects of mannan oligosaccharide or antibiotics in neonatal diets on health and growth of dairy calves. Journal Dairy Science, 86: 40644069.

20. Hou, Y., Y. Yin and G. Wu. 2015. Dietary essentiality of "nutritionally non-essential amino acids" for animals and humans. Experimental Biology and Medicine, 240: 997-1007.

21. Hou, Y., K. Yao, Y. Yin and G. Wu. 2016. Endogenous synthesis of amino acids limits growth, lactation, and reproduction in animals. Advances in Nutrition, 7: 331-342.

22. Karimzadeh, S., M. Rezaei and A. Teomouri Yansari. 2016. Effects of Bioactive Peptides Derived from Canola Meal on performance, digestive enzyme activities, nutrient digestibility, intestinal morphology and gut microflora in broiler chickens. Poultry Science Journal, 4: 27-36.

23. Kim, M.H., C.H. Yun, H.S. Kim, J.H. Kim, S.J. Kang, C.H. Lee, J.Y. Ko and J.K. Ha. 2010. Effects of fermented soybean meal on growth performance, diarrheal incidence and immune response of neonatal calves. Animal Science. Journal, 81: 475-481.

24. Kogan, G. and A. Kocher. 2007. Role of yeast cell wall polysaccharides in pig nutrition and health protection. Livestock Science, 109: 161-165.

25. Larson, L.L., F.G. Owen, J.L. Albright, R.D. Appleman, R.C. Lamb and L.D. Muller. 1977. Guidelines toward more uniformity in measuring and reporting calf experimental data. Journal of Dairy Science, 60: 989-991.

26. Liu, P., X.S. Piao, S.W. Kim, L. Wang, Y.B. Shen, H.S. Lee and S.Y. Li. 2008. Effects of chitooligosaccharide supplementation on the growth performance, nutrient digestibility, intestinal morphology, and fecal shedding of Escherichia coli and Lactobacillus in weaning pigs1. Journal of Animal Science, 86: 2609-2618.

27. Mohamadi Roodposhti, P. and N. Dabiri. 2012. Effects of Probiotic and Prebiotic on Average Daily Gain, Fecal Shedding of Escherichia Coli and Immune System Status in Newborn Female Calves. Asian-Australasian Journal of Animal Sciences, 9: 1255-1261.

28. Mohammed, H.H., B.M. El-Sayed and M.A. Ali. 2013. Effects of commercial feed additives on performance, economic efficiency, blood metabolites and some maintenance behaviour in goats. Journal of Veterinary Science and Medical Diagnosis, 2: 2-7.

29. Moarrab, A., T. Ghoorchi, S. Ramezanpour, F. Ganji and A.R. Koochakzadeh. 2016. Effect of Synbiotic on Performance, Intestinal Morphology, Fecal Microbial Population and Blood Metabolites of Suckling Lambs. Iranian Journal of Applied Animal Science, 6: 621-628.

30. Morrison, S.J., S. Dawson and A.F. Carson. 2010. The effects of mannan oligosaccharide and Streptococcus faecium addition to milk replacer on calf health and performance. Livestock Science, 131: 292-296. 
31. Nargeskhani, A., N. Dabiri, S. Esmaeilkhanian, M.M. Alipour and M. Bojarpour. 2010. Effects of mannanoligosaccharide- $\beta$ glucan or antibiotics on health and performance of dairy calves. Animal Nutrition and Feed Technology, 10: 29-36.

32. NRC, National Research Council (US). Committee on Nutrient Requirements of Small Ruminants. 2007. Nutrient requirements of small ruminants: sheep, goats, cervids, and new world camelids.

33. Neish, A.S. 2009. Microbes in gastrointestinal health and disease. Gastroenterology, 136: 65-80.

34. Pasupuleti, V.K. 2006. Proteins power up. Food Technology, 2: 55-57.

35. Quigley, J.D., C.J. Kost and T.A. Wolfe. 2002. Effects of spray-dried animal plasma in milk replacers or additives containing serum and oligosaccharides on growth and health of calves. Journal Dairy Scince, 85: 413-421.

36. Raeth, M., H. Chester-Jones, PAS, D. Ziegler, B. Ziegler, D. Schimek and D.L. Cook. 2016. P re- and postweaning performance and health of dairy calves fed milk replacers with differing protein sources. The Professional Animal Scientist, 32: 833-841.

37. Rozeboom, D.W., D.T. Shaw, R.J. Tempelman, J.C. Miguel, J.E. Pettigrew and A. Connolly. 2005. Effects of mannan oligosaccharide and an antimicrobial product in nursery diets on performance of pigs reared on three different farms. Journal of animal science, 83: 2637-2644.

38. SAS. 2001. Statistical Analysis System User's Guide: Statistics. SAS Institute, Cary, NC.

39. Silva, J.T.D., C.M.M. Bittar and L.S. Ferreira. 2012. Evaluation of mannan-oligosaccharides offered in milk replacers or calf starters and their effect on performance and rumen development of dairy calves. Revista Brasileira de Zootecnia, 41: 746-752.

40. Swanson, K., C. Grieshop, E. Flickinger, H.P. Healy, K.A. Dawson, N.R. Merchen, N.R. Merchen and G.C. Fahey Jr. 2002. Effects of supplemental fructooligosaccharides plus mannanoligosaccharides on immune function and ileal and fecal microbial populations in adult dogs. Archives of Animal Nutrition, 56: 309-318.

41. Terre, M., M.A. Calvo, C. Adelantado, A. Kocher and A. Bach. 2007. Effects of mannan oligosaccharides on performance and microorganism fecal counts of calves following an enhancedgrowth feeding program. Animal Feed Science Technology, 137: 115-125.

42. Van Soest, P.Jvan, J.B. Robertson and B.A. Lewis. 1991. Methods for dietary fiber, neutral detergent fiber, and non-starch polysaccharide in relation to animal soybean meal on nitrogen utilization by ruminants. Journal of Animal Science, 63: 879-886.

43. Van Loo, J., P. Coussement, L. De Leenheer, H. Hoebregs and G. Smits. 1995. On the presence of inulin and oligofructose as natural ingredients in the western diet. Critical Reviews in Food Science and Nutrition, 35: 525-552.

44. Wang, J.H., C.C. Wu and J. Feng. 2013. Effect of dietary antibacterial peptide and zinc-methionine on performance and serum biochemical parameters in piglets. Czech Journal Animal Science, 5: 30-36.

45. Zhang, B., L.Q. Xue, L.L. Li, Y.G. Chen, G.H. Wen and D.X. Hou. 2007. Effects of soybean small peptides on nitrogen balance, nutrient digestibility and several indices in the portal veinous plasma of goats. Small Ruminant Research, 72: 1-10.

46. Zheng, L., I. Park and S.W. Kim. 2016. Effects of supplemental soy peptide on growth performance and gut health of nursery pigs. Journal Animal Science, 94: 49-56. 


\title{
The Effects of Different Levels of Prebiotic and Peptide Supplementations on Growth Performance, Apparent Digestibility Nutrients and Fecal Score in Suckling Zell Lambs
}

\author{
Mehdi Bahari ${ }^{1}$, Yadollah Chashnidel ${ }^{2}$, Asadollah Teimouri Yansari ${ }^{3}$ and \\ Mohammad Kazemifard ${ }^{4}$ \\ 1, 3 and 4- Ph.D Students in Animal Nutrition, Associate Professor, and Assistant Professor, Department of Animal \\ Science, Sari University of Agricultural Sciences and Natural Resources \\ 2- Assistant Professor, Department of Animal Science, University of Agricultural Sciences and Natural Resources, \\ Sari (Corresponding Author: ychashnde12002@yahoo.com) \\ Received: June 17, $2018 \quad$ Accepted: September 22, 2018
}

\begin{abstract}
This study investigated the effects of different levels of prebiotic and peptide supplementations on growth performance, apparent digestibility of nutrients and fecal score in suckling Zell lambs. A completely randomized experiment was designed with a factorial arrangement of $3 \times 2$ containing 36 male suckling Zell lambs at the age of 10 days and with a mean weight of $4.4 \pm 0.33 \mathrm{~kg}$ for 70 days. The treatments consisted of 1 - control (without prebiotic and peptide), 2-0 $\mathrm{g}$ of prebiotic and $2 \mathrm{~g}$ of peptide, 3-1.5 $\mathrm{g}$ of prebiotic and $0 \mathrm{~g}$ of peptide, 4-1.5 g of prebiotic and $2 \mathrm{~g}$ of peptide, 5-3 $\mathrm{g}$ of prebiotic and 0 of peptide, and 6-3 $\mathrm{g}$ of prebiotic and $2 \mathrm{~g}$ of peptide per day for the experimental lambs in milk replacement. The results of mean feed intake and daily weight gain of experimental lambs showed a significant difference between experimental treatments $(\mathrm{P}<0.05)$, so were higher in treatment of $2 \mathrm{~g}$ peptide and $1.5 \mathrm{~g}$ prebiotic. There was a significant difference in the apparent digestibility nutrients in $\mathrm{DM}, \mathrm{OM}, \mathrm{CP}$ and $\mathrm{ADF}$ peptide and peri-biotic interaction effects $(\mathrm{P}<0.05)$. In results of fecal score, there was a significant decrease in consistency score of $1.5 \mathrm{~g}$ prebiotics $(\mathrm{P}<0.05)$. Carcass traits significantly improved by treatment of $2 \mathrm{~g}$ peptide and $1.5 \mathrm{~g}$ prebiotic. There was no significant difference in the results of feed conversion rario (FCR) and body dimensions. The overall results showed, feed intake significantly increased by treatment of $2 \mathrm{~g}$ peptide and $1.5 \mathrm{~g}$ of prebiotic and improved daily gain and fecal score in some experimental periods as well as carcass traits in lambs.
\end{abstract}

Keywords: Digestibility, Growth performance, Prebiotic, Peptide, Suckling lambs 